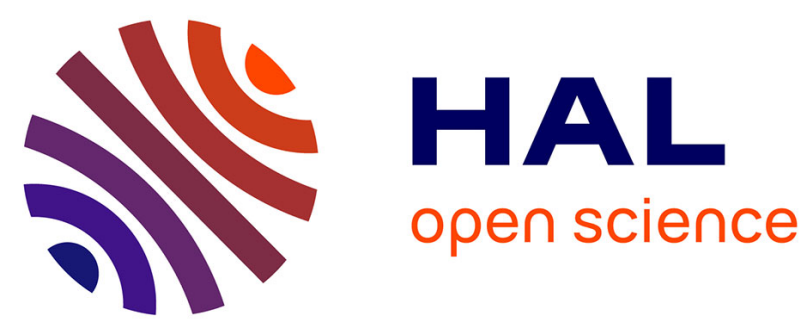

\title{
Nanoplastics are neither microplastics nor engineered nanoparticles
}

\author{
Julien Gigault, Hind El Hadri, Brian Nguyen, Bruno Grassl, Laura \\ Rowenczyk, Nathalie Tufenkji, Siyuan Feng, Mark Wiesner
}

\section{To cite this version:}

Julien Gigault, Hind El Hadri, Brian Nguyen, Bruno Grassl, Laura Rowenczyk, et al.. Nanoplastics are neither microplastics nor engineered nanoparticles. Nature Nanotechnology, 2021, 16 (5), pp.501-507. 10.1038/s41565-021-00886-4 . hal-03237510

\section{HAL Id: hal-03237510 https://hal-univ-pau.archives-ouvertes.fr/hal-03237510}

Submitted on 5 Oct 2021

HAL is a multi-disciplinary open access archive for the deposit and dissemination of scientific research documents, whether they are published or not. The documents may come from teaching and research institutions in France or abroad, or from public or private research centers.
L'archive ouverte pluridisciplinaire $\mathbf{H A L}$, est destinée au dépôt et à la diffusion de documents scientifiques de niveau recherche, publiés ou non, émanant des établissements d'enseignement et de recherche français ou étrangers, des laboratoires publics ou privés. 


\title{
Nanoplastics are neither microplastics nor engineered nanoparticles
}

Julien Gigault ${ }^{*}$, Hind El Hadri², Brian Nguyen ${ }^{3}$, Bruno Grass ${ }^{2}$, Laura Rowenczyk ${ }^{3}$ Nathalie Tufenkji ${ }^{3 *}$, Siyuan Feng, ${ }^{4}$ Mark Wiesner ${ }^{4}$

1- TAKUVIK (UMI CNRS/Université Laval)

Department of Chemistry

1045, av. de la Médecine,

Quebec, Quebec, Canada G1V 0A6

Email : julien.gigault@takuvik.ulaval.ca

2- CNRS- IPREM Pau UMR5152

2 Av. P. Angot

$64000 \mathrm{Pau}$

3- McGill University

Department of Chemical Engineering

3610 University Street

Montreal, Quebec, Canada H3A 0C5

Email: nathalie.tufenkji@mcgill.ca

4- Duke University

Department of Civil and Environmental Engineering

Center for the Environmental Implications of NanoTechnology (CEINT)

Hudson Hall, Room 121

Durham, North Carolina USA

Durham, USA

\begin{abstract}
Increasing concern and research on the subject of plastic pollution has engaged the community of scientists working on the environment, health, and safety (EHS) of nanomaterials. While many of the methods developed in nano EHS work have general applicability to the study of particulate plastics, the nanometric size range has important consequences for both the analytical challenges of studying nano-scale plastics and the environmental implications of these incidental nanomaterials. Related to their size, nanoplastics are distinguished from microplastics with respect to their transport properties, interactions with light and natural colloids, a high fraction of particle molecules on the surface, bioavailability, and diffusion times for the release of plastic additives. Moreover, they are distinguished from engineered nanomaterials because of their high particle heterogeneity and their potential for rapid further fragmentation in the environment. These characteristics impact environmental fate, potential effects on biota and human health, sampling, and analysis. Like microplastics, incidentallyproduced nanoplastics exhibit a diversity of compositions, morphologies, and heterogeneity that is typically absent from engineered nanomaterials. Therefore, nano-scale plastics must be considered as distinct from both microplastics and engineered nanomaterials.
\end{abstract}




\section{Introduction}

While the accumulation of microplastics and larger plastic debris in the world's oceans has garnered much attention, colloidal plastic debris may represent a portion of released plastic that remains unaccounted for based on oceanic circulation models ${ }^{1-4}$. Scientists also estimate that plastic pollution on land and in freshwaters ${ }^{5}$ can be many times greater than the estimated 4.8 to 12.7 million metric tons ${ }^{3}$ of plastic annually emitted to the ocean, yet little is known regarding the levels of colloidal plastics in these environmental compartments. Nanoplastics are the smaller nano-scale fraction of these colloids and are most likely to be incidentally produced from the fragmentation of larger plastic debris. Although complete breakdown of larger plastic debris can take up to hundreds of years, mechanical wear ${ }^{6}$, heat ${ }^{7}$, UV degradation ${ }^{8}$ and, in some cases, biological factors ${ }^{9}$, lead to relatively rapid fragmentation of plastic debris down to the nano-scale.

Our understanding of the interactions between incidental nanoplastics and the environment is in its infancy. Due to methodological challenges ${ }^{10}$, nanoplastics in environmental samples remain largely unquantified, although recent work has reported the chemical signatures of nanoplastic contamination in ocean waters ${ }^{11}$. Due to their similar composition and origin, as well as the nature of the research communities involved, nanoplastics have been largely treated as an extension of microplastics. However, size-dependent properties of nanoplastics distinguish them from microplastics with respect to their transport properties, interactions with light and natural colloids, analytical challenges, bioavailability, potential toxicity, and leaching times for additives. And, unlike engineered nanomaterials (ENMs) which can include polymer formulations, incidentally-produced nanoplastics in the environment are essentially debris from the environmental fragmentation of larger plastic objects. Chemists, biologists, physicists, ecologists, engineers, toxicologists, and other scientific professionals in the community of researchers examining the environmental, health, and safety (EHS) of ENMs have made significant advances over the last twenty years in developing methodologies for studying nanoscale materials and elucidating the environmental behavior of nano-scale objects. ENMs have been the focus of much of this nanoEHS research. The uniform size and composition that can be achieved in making ENMs, has made them excellent tools for studying the behavior of nanoscale particles in complex environments. Conversely, the heterogeneity of most incidental nanomaterials, including nanoplastics, presents numerous challenges to tracking and quantifying these materials in complex environments. Consequently, nanoplastics should be considered as a unique class of contaminants, distinct from both microplastics and ENMs.

\section{Nanoplastics are distinct from microplastics}

An increase in publications dealing with microplastics has coincided with a shift in terminology, and entry of new scientific communities in addressing the issue of plastic waste as a growing environmental concern. For example, polystyrene spheres are increasingly described in the recent scientific literature as either micro- or nano- "plastic" rather than simply as particles or nanoparticles (Figure 1). The labeling of polystyrene spheres as microplastics (Fig 1a) or nanoplastics (Fig. 1b) introduces new terms for materials used in virtually identical studies conducted with a different motivation many decades earlier ${ }^{12}$. The re-casting of the microplastic problem as one that distinctly entails nanoplastics (Figure 1b) may reflect a retooling of the nanoEHS community to apply methods to the problem of plastic debris. Indeed, there is a large body of knowledge gained from studying ENM behavior in the workplace, in consumer products, and in natural and complex environmental systems that can be extended to 
nanoplastics research. In the last two decades, significant analytical developments have been made to characterize, identify and quantify ENMs in aqueous media such as fullerenes ${ }^{13}$, silver nanoparticles ${ }^{14}$, and $\mathrm{TiO}_{2}$ nanoparticles ${ }^{15}$ and to elucidate the environmental fate and impact of these materials. A key lesson learned from ENM research is that properly defining terms early in the trajectory of the research and establishing rigorous ontologies, enables data sharing across communities. It is therefore important to articulate what is meant by the terms nanoplastic, microplastic and their relationship to ENMs.
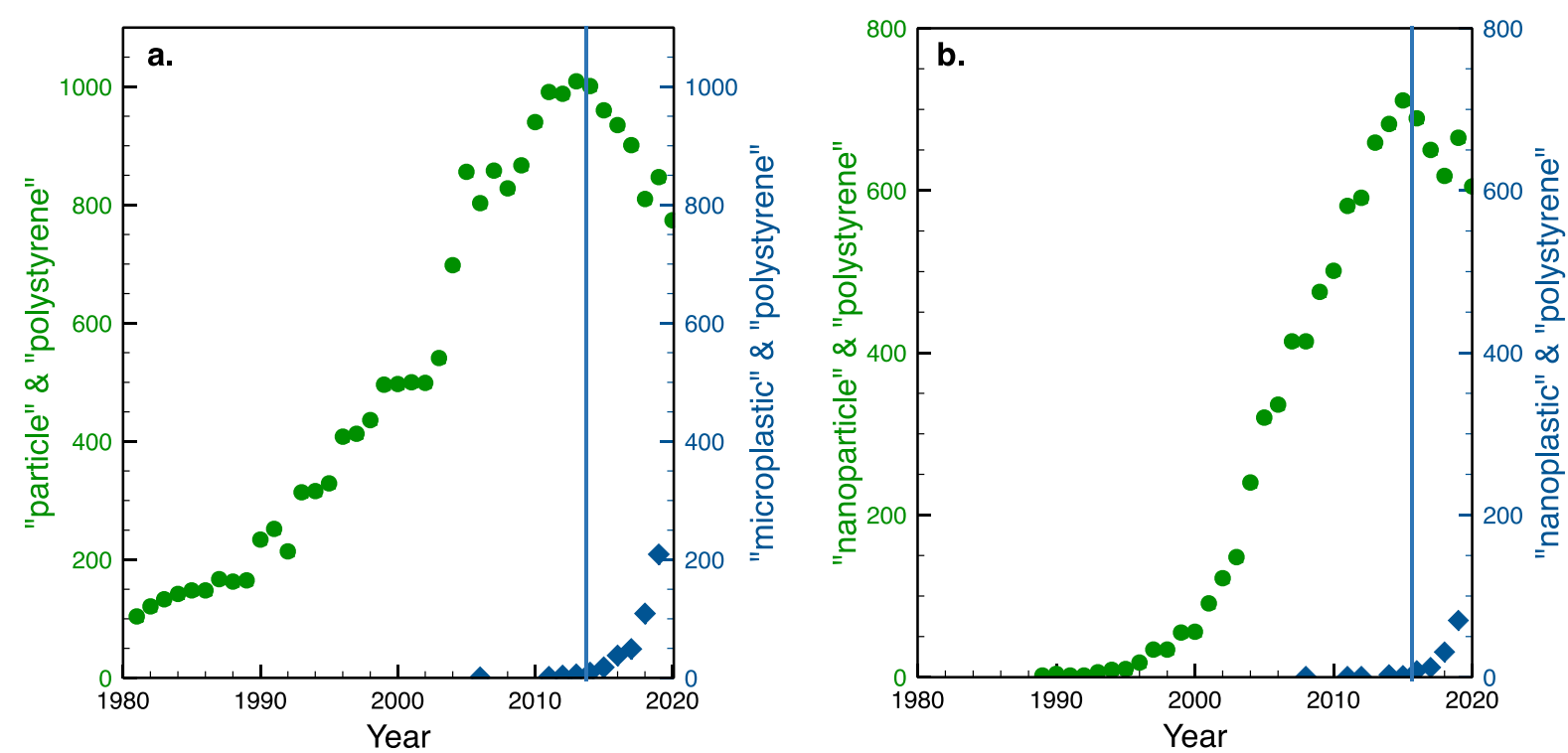

Fig. 1. Number of publications obtained from Scopus that use the terms shown on the $y$-axis in the Title/Abstract/Keywords. (a) particle* AND polystyrene* AND NOT microplastic*(green circle) versus microplastic* \& polystyrene* (blue diamond) and (b) nanoparticle* AND polystyrene* AND NOT nanoplastic* (green circle) vs nanoplastic* \& polystyrene (blue diamond). The light blue vertical line highlights the coincidence between the decrease in the number of publications and the exponential increase in publications that occurs by changing the terms from "particle" and "nanoparticle" to "microplastic" and "nanoplastic".

While all plastics are polymer-based, not all polymers are plastic and nanoplastics are not synonymous with nanopolymers ${ }^{16}$. Plastics will typically include material composed of polymer as well as additives. The term "nanoplastic" has typically been used with reference to solely size, and with some inconsistency as to what the exact size cut-off should be between a nanoplastic and a microplastic, with $100 \mathrm{~nm}$ and $1000 \mathrm{~nm}$ being the most common size cutoffs ${ }^{17-19}$. The US National Nanotechnology Initiative (NNI) defines a nanomaterial as having at least one dimension between 1 and $100 \mathrm{~nm}$ and exhibiting properties not found at larger sizes of the same material. The definition of "nano" typically involves considerations that go beyond arbitrary size cut-offs ${ }^{20}$. While conflicting scientific, commercial, and regulatory considerations complicate the definition of nanomaterials ${ }^{20}$, the distinction between nanomaterials and their larger counterparts is generally held to be dependent on both size and the resulting properties. For example, semi-conductor quantum dots fluoresce at size-dependent wavelengths due to quantum confinement of electrons at particle sizes well below electron wavelengths. Consequently, the properties and behavior of nanomaterials cannot be extrapolated from the properties of their bulk counterparts. In our view, it is these characteristics, that separate "nano" from "micro" regardless of a particular size range ${ }^{20}$. Further, one may differentiate between engineered, incidental, and natural nanoparticles, distinctions that may be blurred as in the case of $\mathrm{C}_{60}$ which can be produced as an ENM, but is also present in combustion products ranging from forest fires to industrial combustion ${ }^{21}$. As incidental nanomaterials, nanoplastics are likely to exhibit size-emergent properties (Figure 2) that will depend on both the origin of the material 
and the pathway to its creation. Characteristics that distinguish nanoplastics from microplastics include:

I. The dominance of Brownian motion over sedimentation and buoyancy characterized by random movements of the particles in a suspension medium;

II. Departure from the geometric/ray approximation between light and matter. For microplastics, the interaction of light and microplastic can be adequately approximated by modeling light as a straight ray. In contrast, with nanoplastics, the wave-nature of light and associated phenomena important in some analytical methods, including diffraction, are significant;

III. A high proportion of molecules on the surface resulting in a higher relative importance of surface interactions compared to physical interactions;

IV. The thickness of the particle diffuse layer may be comparable to the size of environmental macromolecules (leading to adsorption/heteroaggregation), while it is small compared to the size of associated microorganisms (preventing biofilm formation);

V. Sizes compatible with bio-uptake, translocation and transport across biological membranes and;

VI. Short length scales that may speed the diffusive release of plastic additives and nonintentionally added substances in the original bulk plastic.

\section{Nanoplastics have unique characteristics compared to engineered nanomaterials}

While nanoplastics may share many of the properties of ENMs, nanoplastics found in the environment present unique considerations and challenges. To begin with, environmental nanoplastics, largely incidental in origin, represent a vastly higher exposure potential compared to ENMs. Of the 6300 million metric tons of plastic waste generated between 1950 and 2015, approximately 5000 million metric tons were emitted to the environment, where they can eventually break down into nanoplastics ${ }^{2}$. In 2018, plastic production was approximately 359 million metric tons worldwide ${ }^{22}$. In contrast, rough estimates for global production of ENMs of all kinds range from thousands of metric tons per year to no more than $10^{6}$ metric tons. Compared to plastics production that emerged as early as the $1950 \mathrm{~s}^{23}$, ENM production is a relatively recent activity that has expanded rapidly since the 1990s.

Furthermore, environmental nanoplastics as a class of contaminants are substantially more heterogeneous compared to ENMs. ENMs are intentionally created to desired specifications, typically with a uniform composition for a given material. The separation and characterization of ENMs in complex media are facilitated by knowing these specifications and their resulting properties (i.e., optical, magnetic, conductor properties). Standardized techniques adapted to ENMs are now widely used by the scientific community. Note that there exists ENMs composed of polymer types that could be considered "plastic". For example, spherical and monodisperse polystyrene nanoparticles, used in the ENM community, are used as a reference or model material for calibrating analytical tools such as field flow fractionation, size exclusion chromatography, static light scattering, and other techniques, as summarized elsewhere ${ }^{24}$. Due to their high uniformity, these plastic spheres are easy to track during the analyses, but are not representative of the diversity of incidental nanoplastics in the environment ${ }^{25}$. Environmental nanoplastics are generally not intentionally designed and vary greatly in shape, size, polydispersity, additives, adsorbed contaminants, surface properties, and composition as a consequence of different source materials, fragmentation pathways and environmental exposure $^{26}$. The resulting physical and chemical heterogeneity of nanoplastics may influence their reactivity and will certainly affect interactions with natural colloids and organisms. For 
example, weathering induced by UV radiation enhances fragmentation of bulk plastic into micro- and nanoplastics, in addition to modifying material chemical properties such as crystallinity and polarity which significantly influence the adsorption of substances ${ }^{27,28}$. The result is an extremely broad scope of materials to investigate.

These incidental nanoplastics are distinguished from ENMs (Figure 2) by:

VII. High particle heterogeneity originating from variable sources and environmental conditions that result in nano-scale materials with a wide range of sizes, shapes, and overall composition even when the nanoplastics originate from a common source;

VIII. Incidental nanoplastics may include the fragmentation products of engineered (primary) nanoplastics with the potential for further fragmentation in the environment at shorter time scales.

While some researchers are creating model materials intended to be used as nanoplastic proxies $^{25,29-31}$, in contrast with ENMs, there are no "standard" materials that can be used to fully represent environmental nanoplastics or track them. Nevertheless, many factors influence the formation of environmental nanoplastics and since most of these processes are still poorly understood, nanoplastic proxies used in the laboratory can include idealizations that are not fully representative of environmental realities or that are not generalizable to other types of nanoplastics ${ }^{32,33}$. Therefore, as we should not overlook the fact that $\mathrm{CuO}$ nanoparticles can have different effects from $\mathrm{TiO}_{2}$ particles when interpreting experimental results, we should not dismiss the varying impacts that different types of nanoplastics can have. The use of fieldcollected samples, and their subsequent fractionation using a "top-down" approach, followed by their characterization, can provide a baseline comparison for results from experiments using nanoplastic proxies.

\section{Environmental fate and behavior}

The distinct characteristics of nanoplastics will influence their environmental fate and behavior, interactions with biological systems, sampling strategies, analytical methods, experimental and computational modeling approaches that cannot be extrapolated from microplastics or ENMs. Due to the colloidal nature and dominance of Brownian motion over sedimentation and buoyancy, vertical transport of individual nanoplastic particles will be small compared with microplastics composed of the same material (property I in Figure 2). For example, polypropylene and polyethylene have densities less than water, and are therefore expected to float in water, while polyvinyl chloride would be expected to settle because of its higher density $\left(\sim 1.4 \mathrm{~g} / \mathrm{cm}^{3}\right)$. By Stoke's law, a $1 \mathrm{~mm}$ polyvinyl chloride microplastic is calculated to settle at a rate of approximately $22 \mathrm{~cm} / \mathrm{sec}$ in water compared with a $100 \mathrm{~nm}$ nanoplastic which would be expected to settle at a rate of only some $7 \mathrm{~cm}$ per year. Thus nanoplastics, as with other colloidal species, are more likely to remain homogeneously dispersed in aqueous systems ${ }^{18}$ and may be more likely to remain suspended in the atmosphere and form a portion of "ultra-fine" (sub $100 \mathrm{~nm}$ ) particulate matter ${ }^{34}$. However, aggregation with other particles may increase the effective settling rate of nanoplastics. 


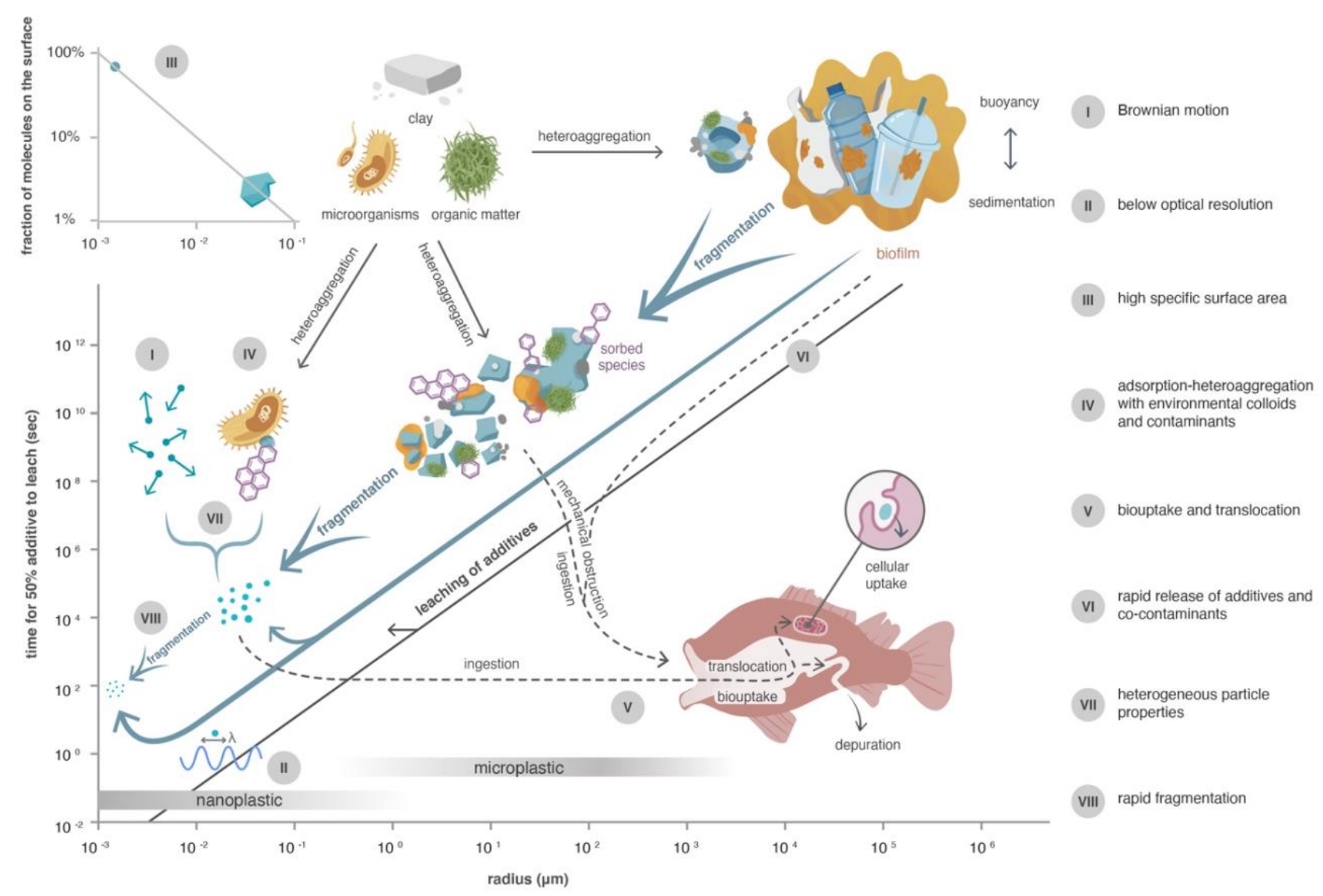

Figure 2. Transformations and characteristics of plastic debris in the environment. The eight defining characteristics of nanoplastics that distinguish them from microplastics and engineered nanomaterials. The time needed to leach one half of the additives initially present in a plastic material is calculated for the representative additive tributyl phosphate ("leaching of additives" curve, characteristic VI). Leaching of tributyl phosphate was calculated for different sized epoxy particles based on internal diffusion-limited transport ${ }^{44}$. Bulk plastics break down into micro- and nanoplastics due to weathering action (UV sunlight, mechanical abrasion, etc.), environmental (heteroaggregation) and biological (bacteria, krill, etc.) processes.

Nanoplastics can be expected to heteroaggregate with natural colloids such as natural organic matter (polysaccharides, humic acids, leonardite, etc.), iron oxides, and clays, and/or anthropogenic material ${ }^{20,35}$ or with aerosols in the atmosphere (property IV in Figure 2). Macromolecules that may associate with nanoplastics will have length scales similar to the nanoplastic, while being much smaller than the size of a microplastic. This may affect the degrees of freedom of the macromolecule and therefore the attachment efficiency between nanoplastics and heteroaggregates. Heteroaggregation and the conformation of charged macromolecules in water is in turn influenced by environmental conditions (i.e., porewater $\mathrm{pH}$, ionic strength, hardness, etc). These factors will disproportionately influence the attachment efficiency of nanoplastics relative to microplastics due to the dominant role of surfaces at the nanoscale. In addition, the collision rate kernel for nanoplastic heteroaggregation will be dominated by Brownian diffusion rather than by settling, buoyancy, or fluid motion. Consequently, nanoplastic distribution in the environment cannot be directly extrapolated from that of microplastics.

The fact that nanoplastics are smaller than most microorganisms, implies differences in the microbial interactions and biofilm formation. Microplastics are large enough to host a community of micro-organisms (i.e., the "plastisphere") ${ }^{36,37}$ and accompanying development 
of complex biofilms. These micro-organisms can form a significant portion of the overall mass and can affect environmental distribution by altering the effective density of microplastics, but the overall particle is still primarily the microplastic ${ }^{21}$. In contrast, nanoplastics may evolve to be minor components of a larger nanoplastic-microbial complex and, like ENMs ${ }^{22}$, may make up a small percentage of the mass of heteroaggregates. The environmental fate of these heteroaggregates may not have a strong dependence on the properties of nanoplastics (property IV in Figure 2). Figure 3 illustrates the contribution of natural organic matter (NOM) relative to a volume of plastic debris. It is interesting to note the shift in the slope of the curve which occurs at the transition between nanoplastics and microplastics. The NOM is a minor component compared to the host plastic from the millimeter to the micrometer scales. As the plastic size decreases, the contribution of the NOM increases and it becomes analytically challenging to discriminate the plastic component, especially given similar carbon-based structures. Unlike with microplastics, the transport, uptake and accumulation pathways of nanoplastics will be highly influenced by NOM relative to the intrinsic properties of the plastic. The outsized influence of NOM on environmental fate can lead to inappropriate strategies during sampling, analysis and lifecycle assessments if only the plastic component of heteroaggregates is considered.

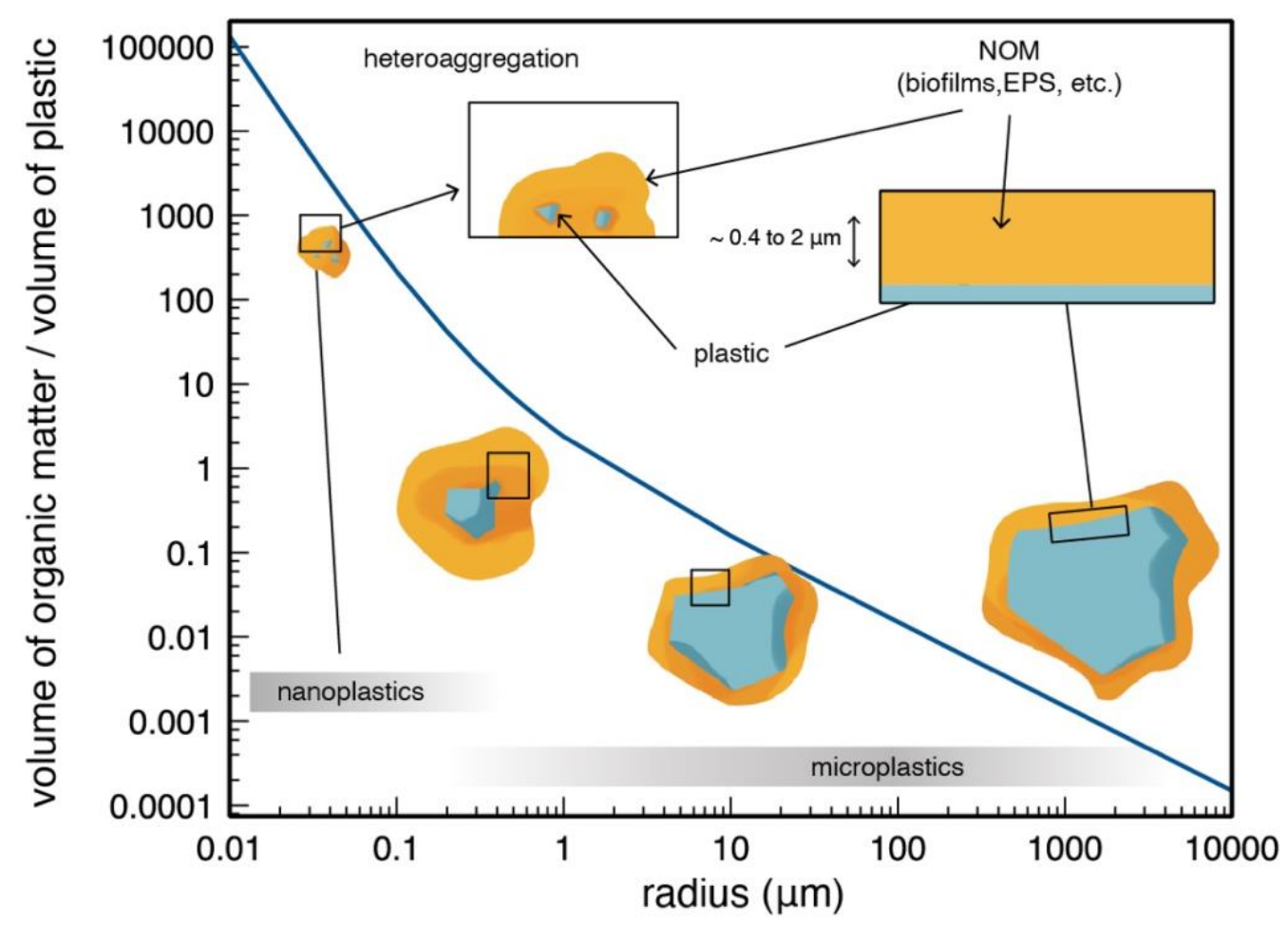

Figure 3. Relative proportion of natural organic matter compared to plastic according to the size (radius) of plastic debris. The relative proportion is represented by the ratio of the volume of the natural organic matter to the volume of plastic for a given particle.

Plastics often contain a wide variety of chemical additives as well as non-intentionally added substances such as degradation products, reaction by-products and/or impurities ${ }^{26,38,39}$. Since these other chemicals are not generally covalently bound to the polymer matrix, they may leach out of the plastic ${ }^{26,40}$. These leached chemicals include bisphenol A, phthalates, nonylphenols, 
brominated flame retardants, to name a few ${ }^{26,40}$. We have used analytical solutions describing leaching of sorbed materials from a homogeneous particle matrix (e.g., Crank, 1975) $)^{41}$ in conjunction with literature data describing the leaching of additives from plastic pipe materials to obtain estimates of additive leaching from particles of various sizes ${ }^{42}$. We estimate the rates that additives leach from nanoplastics to be many orders of magnitude greater than the leaching rate from microplastics due to the smaller distances for diffusive transport (property VI in Figure 2). These rates, predicted in many cases to be comparable to the inverse residence time of digestion, depend on both the type of additive and the plastic and may vary by two or more orders of magnitude. Thus, additive release can be anticipated in many cases to occur in organisms as well as in the environment. Combined with increased bioavailability and the enhanced accessibility to tissues, nanoplastics may be expected to deliver locally high doses of leached compounds compared with microplastics and therefore exhibit differences in apparent dose-response. The specificity of releases to tissues and the consequences of these localized releases have not been studied.

\section{Biological Consequences}

Size has been established as a key factor in the ability of nano-sized particles to translocate in organisms ${ }^{43}$. Bio-uptake, biomagnification and maternal transfer have all been observed for ENMs $^{26,35,44,45}$. Approaching the size of natural proteins, nanoplastics may be small enough to travel across biological membranes via passive diffusion and access certain endocytosis pathways $^{46,47}$ (property V in Figure 2). Johnston et al. found that fresh fumes containing nanoscale polytetrafluorethylene were more toxic to rodents than aged fumes which contained larger, coagulated aggregates of polytetrafluorethylene ${ }^{48}$. Bioavailability of ENMs to plants appears to increase as particle diameter decreases below $20 \mathrm{~nm}^{49}$. Increased bioavailability is consistent with the higher toxicities often found in ENMs compared to their larger counterparts. For example, in plants exposed to $\mathrm{CuO}$, nanoscale particles resulted in greater toxicity compared to micron-sized particles ${ }^{44}$. Rist et al. found that nanoscale polystyrene caused decreased feeding rates and were egested to a lesser degree in contrast to microscale polystyrene $^{50}$. Moreover, nanomaterials can interact with subcellular components and trigger responses including reactive oxygen species production.

A considerable portion of the molecules in nanoplastics are exposed to the surface resulting in greatly enhanced surface reactivity compared to their micro- and macroscale counterparts leading to heightened importance of surface chemistries on interactions with biological systems (property III in Figure 2). For example, Miao et al. (2019) showed clear effects on the biological activity of biofilms for nanoscale polystyrene beads $(100 \mathrm{~nm})$ as opposed to larger polystyrene particles and for positively charged nanoscale polystyrene compared to their carboxylfunctionalized counterparts ${ }^{51}$. Interactions with proteins and changes in protein conformation, production of reaction oxygen species, and acting as a vector for other contaminants (Trojan horse effects) are among the phenomena that have been observed for ENMs that may also come into play with nanoplastics. These effects could potentially enhance the toxicity of the nanoplastics.

\section{Sampling and analysis of nanoplastics}

Table 1 summarizes how the characteristics of nanoplastics that distinguish them from microplastics (I to VI) and ENMs (VII-VIII) impact the analytical approaches used to study 
their physicochemical properties and environmental fate and behavior. Brownian motion distinguishes separation and analytical techniques used for nanoplastics studies in contrast to microplastics. While the small size of nanoplastics generally makes dead-end filtration (typically used for microplastic separation) impractical, the resulting dominance of Brownian motion allows separation and analytical techniques typically applied to ENMs ${ }^{52-55}$. These techniques include: crossflow ultrafiltration, asymmetric flow field flow fractionation ${ }^{56,57}$, nanoparticle tracking analysis and dynamic light scattering.

The nanoscale size of nanoplastics limits far-field geometric optics-based imaging and chemical analysis techniques. As nanoscale sizes are smaller than the wavelength of visible or infrared light, optical diffraction becomes significant, resulting in an Abbe diffraction resolution limit of $200 \mathrm{~nm}$ for analysis techniques that rely on laser spot sizes (micro-Raman) or transmitted/reflected light (micro-FTIR, brightfield microscopy). These techniques are popular in microplastics analysis as physical and chemical information can be obtained with a single instrument. Consequently, as with ENMs, electron microscopy or diffraction unlimited light microscopy (e.g., stimulated emission depletion microscopy, photoactivated localization microscopy) is required to image nanoplastics. These far field light techniques are typically not compatible with full chemical characterization of nanoplastics. Near field techniques avoid diffraction limitations on resolution by confining light to an evanescent field. Recent developments of these techniques show promising results for chemical and topographic characterizations of nanoplastics (i.e., spatial resolution limit of 10-20 nm for AFM-IR and AFM-Raman $)^{58}$. However, near field techniques require samples to be scanned by the evanescent field emitted from probes which limits their throughput and ability to analyze morphologically complex samples.

Overall, as with ENMs, a multi-parameter analytical approach is required to fully characterize nanoplastics in environmental samples ${ }^{59,60}$. This includes determining physical and chemical characteristics while retaining information about the initial dispersion state and nanomaterialmatrix interactions. Multiple techniques can be combined to elucidate multiple parameters from environmental nanoplastics. Consequently, selection of sampling and analytical techniques should consider compatibility with other complementary techniques. For example, field flow fractionation, recently applied for nanoplastics ${ }^{56}$, itself allows size separation and characterization of materials in the colloidal size range but can also be coupled to other techniques including light scattering (provides information on size and shape) and mass spectrometry (provides information on composition and quantity). Depending on the detectors used (on-line or off-line), different particle properties can be characterized, such as: inorganic element concentration with ICP-MS, polymer identification with pyrolysis-GC-MS and shape information with the combined use of DLS and MALS.

Coupling of techniques is commonplace for analysis of natural colloids and inorganic nanomaterials in environmental media where so called "hyphenated" analysis techniques are the norm. Inductively coupled plasma-mass spectrometry (ICP-MS) coupled to flow field fractionation is one such combination that allows size discrimination and chemical characterization of inorganic environmental nanomaterials at exceptionally high sensitivity. Similarly, pyrolysis-gas chromatography-mass spectrometry (Py-GC-MS), an established characterization method for organic material, coupled to flow field flow fractionation is gaining use to study nanoplastics ${ }^{61}$. Moreover, there is increasing interest in taking advantage of the sensitivity of ICP-MS in the nanoplastics context. Recently, Mitrano et al. synthesized palladium-doped nanoplastics compatible with ICP-MS detection ${ }^{31}$. However, ICP-MS has yet to be applied to environmental samples as an inorganic tracer for plastic. Nevertheless, potential 
exists for applying ICP-MS to analyzing nanoplastics in environmental samples, particularly those originating from plastic using metal-based dopants, or nanofillers or by using adsorbed metals $^{62}$ as a proxy. Moreover, ICP-MS, or other mass spectrometry techniques, could be coupled to techniques established for ENM analysis such as the electrospray ionizationdifferential mobility analyzer to obtain size information.

\section{Outlook}

Incidental nanoparticles produced from the fragmentation of plastic waste are an important element in the life cycle of plastic wastes. Lessons learned from 20 years of nanoEHS work should be applied to understanding the dimensions of the problem of plastic wastes. One such lesson is that international, interdisciplinary teams are able to tap specific areas of expertise that may be sparsely distributed across the world. Researchers studying nanoplastics in the environment can help facilitate this needed knowledge transfer by bringing in personnel, in the form of hiring and visiting researchers, with nanoEHS expertise within nanoplastics research groups as well as directly reaching out to nanoEHS research groups for collaborative opportunities.

The establishment of clear terminology and methods that can be harmonized across groups is critical in facilitating such collaborations, data sharing and data interpretation. Size is integral to the definition of nanoplastic; however, we cannot, as for ENMs, be limited by arbitrary size cut-offs (e.g., $100 \mathrm{~nm}$ or $1000 \mathrm{~nm}$ ). It is more meaningful to rely on the particle characteristics to define a nanoplastic. The defining characteristics of incidental nanoplastics which distinguish them from microplastics are described in Figure 2.

These characteristics guide the development and application of analytical methods, sampling procedures, modeling approaches, and data curation that are directly relevant to the study of nanoplastics in the environment some of which carries over from the nanoEHS field. The experience gained from nanoEHS work has underscored important differences in the environmental behavior of nano-scale materials compared to larger particles of identical composition, a distinction that will be important in investigating the prevalence, fate, and impacts of nanoplastics. However, the instability of incidental nanoplastics in the environment and their particle heterogeneity present additional challenges distinct from the ENMs typically studied in the nanoEHS field. Consequently, studying environmental nanoplastics must also integrate lessons learned in dealing with the ubiquity and diversity of environmental microplastics. 
Table 1. Analytical consequences of the nanoplastic defining characteristics.

\begin{tabular}{|c|c|c|}
\hline $\begin{array}{l}\text { Nanoplastic defining } \\
\text { characteristics }\end{array}$ & Analytical Possibilities & Complications \\
\hline I. Brownian motion & $\begin{array}{l}\text { Enables sizing by SLS, DLS, NTA, } \\
\text { and chromatography-based separation } \\
\text { (AF4, SEC, HDC) and } \\
\text { electrophoretic mobility measurement } \\
\text { (CE, DMA). }\end{array}$ & $\begin{array}{l}\text { More limited density separation } \\
\text { (i.e., sedimentation, centrifugation) }\end{array}$ \\
\hline $\begin{array}{l}\text { II. Below geometric } \\
\text { optical resolution }\end{array}$ & $\begin{array}{l}\text { Can use SLS, DLS, AFM, electron } \\
\text { microscopy, PALM, STORM, STED, } \\
\text { and hyperspectral imaging with dark } \\
\text { field microscopy. }\end{array}$ & $\begin{array}{l}\text { Prevents resolution by diffraction- } \\
\text { limited optical methods (conventional } \\
\text { light microscopy) and characterization } \\
\text { by Infrared/Raman diffraction-limited } \\
\text { laser spot. }\end{array}$ \\
\hline $\begin{array}{l}\text { III. High specific } \\
\text { surface area }\end{array}$ & $\begin{array}{l}\text { Enhances surface interactions. } \\
\text { Facilitates dispersion fixation on a } \\
\text { substrate (e.g. sample drying on a } \\
\text { SEM or TEM grid). }\end{array}$ & $\begin{array}{l}\text { Faster surface chemistry changes (e.g., } \\
\text { chemical oxidation). } \\
\text { Risk of sample alteration and loss } \\
\text { (attachment) during analysis }\end{array}$ \\
\hline $\begin{array}{l}\text { IV. Adsorption- } \\
\text { heteroaggregation }\end{array}$ & $\begin{array}{l}\text { Can be tracked by fluorescence } \\
\text { microscopy, using adsorbed } \\
\text { fluorophores, ICP-MS using adsorbed } \\
\text { metal, hyperspectral imaging. } \\
\text { Enables the use of adsorption-based } \\
\text { samplers. }\end{array}$ & $\begin{array}{l}\text { Interference from background } \\
\text { material, } \mathrm{C} \text { in particular. }\end{array}$ \\
\hline $\begin{array}{l}\text { V. Bio-uptake and } \\
\text { translocation }\end{array}$ & $\begin{array}{l}\text { Relatively lower variability in body } \\
\text { burden }\end{array}$ & $\begin{array}{l}\text { Extraction/purification due to lower } \\
\text { sizes and concentrations, difficulties } \\
\text { differentiating between C-based } \\
\text { particles and tissues. }\end{array}$ \\
\hline $\begin{array}{l}\text { VI. Rapid release of } \\
\text { additives and co- } \\
\text { contaminants }\end{array}$ & $\begin{array}{l}\text { Simplifies characterization of } \\
\text { additives and co-contaminants by } \\
\text { ICP-MS, LC-MS, and Py-GC-MS. }\end{array}$ & Complicates ecotoxicity assessment. \\
\hline $\begin{array}{l}\text { VII. Heterogeneous } \\
\text { particle properties }\end{array}$ & $\begin{array}{l}\text { Enables detection and quantification } \\
\text { by co-localization of target } \\
\text { components by single particle } \\
\text { analysis (e.g., a metal additive in a } \\
\text { polymer matrix) }\end{array}$ & $\begin{array}{l}\text { Global characterization difficult - } \\
\text { multiple sampling points required. } \\
\text { Difficult to acquire environmentally- } \\
\text { relevant material for ecotoxicity and } \\
\text { fate assessments. }\end{array}$ \\
\hline $\begin{array}{l}\text { VIII. Rapid } \\
\text { fragmentation due to } \\
\text { environmental } \\
\text { stressors }\end{array}$ & $\begin{array}{l}\text { Bulk plastics and microplastics can } \\
\text { be fragmented to obtain } \\
\text { representative nanoplastics }\end{array}$ & $\begin{array}{l}\text { Unstable samples (e.g., size } \\
\text { distribution, disaggregation). } \\
\text { Increases potential for sample damage } \\
\text { during extraction (e.g., by digestion) }\end{array}$ \\
\hline
\end{tabular}




\section{References}

1. Eriksen, M. Plastic Pollution in the World's Oceans: More than 5 Trillion Plastic

Pieces Weighing over 250,000 Tons Afloat at Sea. PLOS ONE 9, e111913, (2014).

2. Geyer, R., Jambeck, J. R. \& Law, K. L. Production, use, and fate of all plastics ever made. Sci Adv 3, e1700782, (2017).

3. Jambeck, J. R. Plastic waste inputs from land into the ocean. Science 347, 768-771 (2015).

4. Sebille, E. van. A global inventory of small floating plastic debris. Env. Res Lett 10, 124006 (2015).

5. Horton, A. A., Walton, A., Spurgeon, D. J., Lahive, E. \& Svendsen, C. Microplastics in freshwater and terrestrial environments: Evaluating the current understanding to identify the knowledge gaps and future research priorities. Sci Total Env. 586, 127-141 (2017).

6. Ekvall, M. T. Nanoplastics formed during the mechanical breakdown of daily-use polystyrene products. Nanoscale Adv 1, 1055-1061 (2019).

7. Hernandez, L. M. et al. Plastic Teabags Release Billions of Microparticles and Nanoparticles into Tea. Environ. Sci. Technol. 53, 12300-12310 (2019).

8. Lambert, S. \& Wagner, M. Formation of microscopic particles during the degradation of different polymers. Chemosphere 161, 510-517 (2016).

9. Dawson, A. L. Turning microplastics into nanoplastics through digestive fragmentation by Antarctic krill. Nat Commun 9, 1-8 (2018).

10. Nguyen, B. et al. Separation and Analysis of Microplastics and Nanoplastics in Complex Environmental Samples. Acc. Chem. Res. 52, 858-866 (2019).

11. Ter Halle, A. et al. Nanoplastic in the North Atlantic Subtropical Gyre. Environ. Sci. Technol. 51, 13689-13697 (2017).

12. Petosa, A. R., Jaisi, D. P., Quevedo, I. R., Elimelech, M. \& Tufenkji, N. Aggregation and Deposition of Engineered Nanomaterials in Aquatic Environments: Role of Physicochemical Interactions. Environ. Sci. Technol. 44, 6532-6549 (2010).

13. Chen, Z., Westerhoff, P. \& Herckes, P. Quantification of C60 fullerene concentrations in water. Env. Toxicol Chem 27, 1852-1859 (2008).

14. Benn, T. M. \& Westerhoff, P. Nanoparticle silver released into water from commercially available sock fabrics. Env. Sci Technol 42, 4133-4139 (2008).

15. Wang, Y., Westerhoff, P. \& Hristovski, K. D. Fate and biological effects of silver, titanium dioxide, and C60 (fullerene) nanomaterials during simulated wastewater treatment processes. J Hazard Mater 201-202, 16-22 (2012).

16. Gangadoo, S. et al. Nano-plastics and their analytical characterisation and fate in the marine environment: From source to sea. Sci. Total Environ. 732, 138792 (2020).

17. Gigault, J. et al. Current opinion: What is a nanoplastic? Environ. Pollut. 235, 1030 1034 (2018).

18. Rist, S. \& Hartmann, N. B. Aquatic Ecotoxicity of Microplastics and Nanoplastics: Lessons Learned from Engineered Nanomaterials. in Freshwater Microplastics : Emerging Environmental Contaminants? (eds. Wagner, M. \& Lambert, S.) 25-49 (Springer International Publishing, 2018). doi:10.1007/978-3-319-61615-5_2.

19. Hartmann, N. B. et al. Are We Speaking the Same Language? Recommendations for a Definition and Categorization Framework for Plastic Debris. Environ. Sci. Technol. 53, 10391047 (2019).

20. Auffan, M. et al. Towards a definition of inorganic nanoparticles from an environmental, health and safety perspective. Nat. Nanotechnol. 4, 634-641 (2009).

21. Isaacson, C. W., Kleber, M. \& Field, J. A. Quantitative Analysis of Fullerene Nanomaterials in Environmental Systems: A Critical Review. Environ. Sci. Technol. 43, 6463-6474 (2009). 
22. Publications :: PlasticsEurope.

https://www.plasticseurope.org/en/resources/publications/1804-plastics-facts-2019.

23. Resnik, D. B. How Should Engineered Nanomaterials Be Regulated for Public and Environmental Health? AMA J Ethics 21, 363-369 (2019).

24. Mourdikoudis, S., Pallares, R. M. \& Thanh, N. T. K. Characterization techniques for nanoparticles: comparison and complementarity upon studying nanoparticle properties.

Nanoscale 10, 12871-12934 (2018).

25. Sander, M., Kohler, H.-P. E. \& McNeill, K. Assessing the environmental transformation of nanoplastic through 13 C-labelled polymers. Nat. Nanotechnol. 14, 301303 (2019).

26. Rochman, C. M. et al. Rethinking microplastics as a diverse contaminant suite. Environ. Toxicol. Chem. 38, 703-711 (2019).

27. Liu, P. et al. Effect of weathering on environmental behavior of microplastics: Properties, sorption and potential risks. Chemosphere 242, 125193 (2020).

28. Holmes, L. A., Turner, A. \& Thompson, R. C. Interactions between trace metals and plastic production pellets under estuarine conditions. Mar. Chem. 167, 25-32 (2014).

29. Balakrishnan, G., Déniel, M., Nicolai, T., Chassenieux, C. \& Lagarde, F. Towards more realistic reference microplastics and nanoplastics: preparation of polyethylene micro/nanoparticles with a biosurfactant. Env. Sci Nano 6, 315-324 (2019).

30. Pessoni, L. et al. Soap- and metal-free polystyrene latex particles as a nanoplastic model. Environ. Sci. Nano 6, 2253-2258 (2019).

31. Mitrano, D. M. et al. Synthesis of metal-doped nanoplastics and their utility to investigate fate and behaviour in complex environmental systems. Nat. Nanotechnol. 14, 362368 (2019).

32. Wagner, S. \& Reemtsma, T. Things we know and don't know about nanoplastic in the environment. Nat Nanotechnol 14, 300-301 (2019).

33. Koelmans, A. A. Proxies for nanoplastic. Nat Nanotechnol 14, 307-308 (2019).

34. Azimi, P., Zhao, D., Pouzet, C., Crain, N. E. \& Stephens, B. Emissions of Ultrafine Particles and Volatile Organic Compounds from Commercially Available Desktop ThreeDimensional Printers with Multiple Filaments. Env. Sci Technol 50, 1260-1268 (2016). 35. Alimi, O. S., Farner Budarz, J., Hernandez, L. M. \& Tufenkji, N. Microplastics and Nanoplastics in Aquatic Environments: Aggregation, Deposition, and Enhanced Contaminant Transport. Environ. Sci. Technol. 52, 1704-1724 (2018).

36. Zettler, E. R., Mincer, T. J. \& Amaral-Zettler, L. A. Life in the "Plastisphere": Microbial Communities on Plastic Marine Debris. Environ. Sci. Technol. 47, 7137-7146 (2013).

37. Amaral-Zettler, L. A., Zettler, E. R. \& Mincer, T. J. Ecology of the plastisphere. Nat. Rev. Microbiol. 18, 139-151 (2020).

38. Muncke, J. Exposure to endocrine disrupting compounds via the food chain: Is packaging a relevant source? Sci. Total Environ. 407, 4549-4559 (2009).

39. Zimmermann, L., Dierkes, G., Ternes, T. A., Völker, C. \& Wagner, M. Benchmarking the in Vitro Toxicity and Chemical Composition of Plastic Consumer Products. Environ. Sci. Technol. 53, 11467-11477 (2019).

40. Hirai, H. et al. Organic micropollutants in marine plastics debris from the open ocean and remote and urban beaches. Mar. Pollut. Bull. 62, 1683-1692 (2011).

41. Crank J.-the Mathematics of Diffusion-Elsevier(1975) | Diffusion | Laplace Transform. Scribd.

42. Mercea, P. V. et al. Modelling migration of substances from polymers into drinking water. Part 1 - Diffusion coefficient estimations. Polym. Test. 65, 176-188 (2018).

43. Al-Sid-Cheikh, M. et al. Uptake, Whole-Body Distribution, and Depuration of 
Nanoplastics by the Scallop Pecten maximus at Environmentally Realistic Concentrations. Environ. Sci. Technol. 52, 14480-14486 (2018).

44. Karlsson, H. L., Gustafsson, J., Cronholm, P. \& Möller, L. Size-dependent toxicity of metal oxide particles-a comparison between nano- and micrometer size. Toxicol Lett $\mathbf{1 8 8}$, 112-118 (2009).

45. Ruenraroengsak, P. Respiratory epithelial cytotoxicity and membrane damage (holes) caused by amine-modified nanoparticles. Nanotoxicology 6, 94-108 (2012).

46. Jiang, W., Kim, B. Y. S., Rutka, J. T. \& Chan, W. C. W. Nanoparticle-mediated cellular response is size-dependent. Nat Nanotechnol 3, 145-150 (2008).

47. Zhao, J. \& Stenzel, M. H. Entry of nanoparticles into cells: the importance of nanoparticle properties. Polym Chem 9, 259-272 (2018).

48. Johnston, C. J. et al. Pulmonary effects induced by ultrafine PTFE particles. Toxicol. Appl. Pharmacol. 168, 208-215 (2000).

49. Schwab, F. Barriers, pathways and processes for uptake, translocation and accumulation of nanomaterials in plants-Critical review. Nanotoxicology 10, 257-278 (2016). 50. Rist, S., Baun, A. \& Hartmann, N. B. Ingestion of micro- and nanoplastics in Daphnia magna - Quantification of body burdens and assessment of feeding rates and reproduction. Environ. Pollut. 228, 398-407 (2017).

51. Miao, L. et al. Acute effects of nanoplastics and microplastics on periphytic biofilms depending on particle size, concentration and surface modification. Environ. Pollut. 255, 113300 (2019).

52. Astefanei, A. et al. Characterization of aggregates of surface modified fullerenes by asymmetrical flow field-flow fractionation with multi-angle light scattering detection. $J$. Chromatogr. A 1408, 197-206 (2015).

53. Bolea, E., Jiménez-Lamana, J., Laborda, F. \& Castillo, J. R. Size characterization and quantification of silver nanoparticles by asymmetric flow field-flow fractionation coupled with inductively coupled plasma mass spectrometry. Anal Bioanal Chem 401, 2723-2732 (2011).

54. Kammer, F. von der, Legros, S., Hofmann, T., Larsen, E. H. \& Loeschner, K. Separation and characterization of nanoparticles in complex food and environmental samples by field-flow fractionation. TrAC Trends Anal Chem 30, 425-436 (2011).

55. Baalousha, M., Stolpe, B. \& Lead, J. R. Flow field-flow fractionation for the analysis and characterization of natural colloids and manufactured nanoparticles in environmental systems: A critical review. J Chromatogr A 1218, 4078-4103 (2011).

56. Gigault, J., El Hadri, H., Reynaud, S., Deniau, E. \& Grassl, B. Asymmetrical Flow Field Flow Fractionation Methods to Characterize Submicron Particles: Application to Carbon-Based Aggregates and Nanoplastics. Anal Bioanal Chem 409, 6761-6769 (2017). 57. Correia, M. \& Loeschner, K. Detection of nanoplastics in food by asymmetric flow field-flow fractionation coupled to multi-angle light scattering: possibilities, challenges and analytical limitations. Anal. Bioanal. Chem. (2018) doi:10.1007/s00216-018-0919-8.

58. Dazzi, A. \& Prater, C. B. AFM-IR: Technology and Applications in Nanoscale Infrared Spectroscopy and Chemical Imaging. Chem Rev 117, 5146-5173 (2017).

59. Domingos, R. F. et al. Characterizing Manufactured Nanoparticles in the Environment: Multimethod Determination of Particle Sizes. Environ. Sci. Technol. 43, $7277-$ 7284 (2009).

60. Stone, V. et al. Nanomaterials for environmental studies: classification, reference material issues, and strategies for physico-chemical characterisation. Sci. Total Environ. 408, 1745-1754 (2010).

61. Mintenig, S. M., Bäuerlein, P. S., Koelmans, A. A., Dekker, S. C. \& Van Wezel, A. P. Closing the gap between small and smaller: towards a framework to analyse nano- and 
microplastics in aqueous environmental samples. Environ. Sci. Nano 5, 1640-1649 (2018).

62. Davranche, M. et al. Are nanoplastics able to bind significant amount of metals? The lead example. Environ. Pollut. 249, 940-948 (2019). 